\title{
Food deprivation and conditioned flavor preferences based on sweetened and unsweetened foods
}

\author{
ELIZABETH D. CAPALDI, JOAN SHEFFER, and JACQUELINE OWENS \\ University of Florida, Gainesville, Florida
}

\begin{abstract}
In four experiments, rats' preferences for flavors consumed under high deprivation versus low deprivation were measured. In Experiment 1, rats preferred flavors received in unsweetened food under high deprivation to flavors received in unsweetened food under low deprivation. This preference did not vary with amount of food used to deliver the flavorg (1-g vs. 16-g wet mash). Sweetening the food ( $0.10 \%$ saccharin) eliminated this preference when $16 \mathrm{~g}$ of mash was received, but not when $1 \mathrm{~g}$ of mash was received (Experiments 2 and 3 ). Sweetening the mash even more $(0.15 \%$ saccharin) eliminated the preference when $1 \mathrm{~g}$ of mash was received, as well as when $20 \mathrm{~g}$ of mash was received. We suggested that the reinforcing value of sweetness is reduced by increasing deprivation level.
\end{abstract}

The reward value of food should increase with increasing food deprivation, according to many theorists. Bolles (1972), for example, suggested that deprivation is one way to increase the reward value of a goal. Food deprivation, accordingly, should enhance the reward value of food.

We were interested here in whether or not deprivation enhances the reinforcing effect of food. That is, we were interested in whether or not deprivation enhances the learning produced by food. To answer this question, two different flavors were associated with the same food under two different deprivation levels. Subsequently, preference between the flavors was measured under common deprivation levels.

Revusky (1967) reported the first study measuring the effects of deprivation on conditioning (learning) of food preferences. He gave rats grape juice or milk before or after a meal (thus, high deprivation was before feeding, low deprivation following feeding). Later, rats' preference for the flavor given before feeding (under high deprivation) was increased relative to the flavor given after feeding (under low deprivation).

When flavors are given before and after feeding, factors other than level of food deprivation can affect conditioned preferences. The flavor given before feeding can be associated with the subsequent large feeding; the flavor given after feeding can be associated with effects of having just completed a meal. In a series of experiments, Capaldi and Myers (1982) and Capaldi, Myers, Campbell, and Sheffer (1983) gave flavors either separately from feeding or before and after feeding. In these studies,

This research was supported in part by Grant MH 39453 to the first author from the National Institute of Mental Health. Requests for reprints should be sent to Elizabeth D. Capaldi, Department of Psychology, University of Florida, Gainesville, FL 32611-2065. saccharin or sucrose solutions were used to deliver the flavors. Rats preferred the flavor received under low deprivation to that received under high deprivation when flavors were given separately from feeding. When flavors were given immediately preceding and following a meal, rats preferred the flavor given under high deprivation (before feeding). Capaldi and Myers (1982) suggested that there might be some unpleasant reaction to receiving sweet solutions under high deprivation when no meal follows, or that sweet solutions may be more reinforcing under lower deprivation.

The purpose of the present experiments was to further investigate the effects of food deprivation on learning of conditioned food preferences. We were interested in how the learning of conditioned flavor preferences varied with deprivation when foods, rather than saccharin or sucrose solutions, were used to deliver the flavors. As in Capaldi and Myers's (1982) and Capaldi et al.'s (1983) experiments, flavors were given separately from the daily feeding under different deprivation levels.

\section{EXPERIMENT 1}

In Experiment 1, all rats received unsweetened food, one flavor under high deprivation and one flavor under low deprivation. Subsequently, preference between the flavors was measured under both high and low deprivation. Six different groups were run, comprising a $3 \times 2$ factorial design. The first factor was the deprivation levels associated with the flavors -2 vs. $43 \mathrm{~h}, 2$ vs. $26 \mathrm{~h}$, and $24 \mathrm{vs} .43 \mathrm{~h}$. The second factor was the amount of wet mash used to deliver the flavor-1 or $16 \mathrm{~g}$ of mash. We were interested in how conditioned flavor preferences based on unsweetened food varied with degree of deprivation and amount of food associated with the flavor. No previous study has simultaneously measured the effects 
of deprivation level and amount of food on conditioned flavor preferences.

\section{Method}

Subjects. The subjects were 60 naive Sprague-Dawley rats (Harlan Sprague-Dawley, Indianapolis, IN). They were 77 days old upon arrival and 81 days old at the start of the experiment.

Materials. Foods were banana and vanilla mash. Mash consisted of $50 \%$ powdered lab chow, $47 \%$ water, and $3 \%$ banana or vanilla flavoring. Flavorings were Saure's brand banana or vanilla imitation flavoring. Mash was presented in zinc canning-jar lids taped to metal strips that hung over the front of the cage allowing the jar lid to rest on the cage floor.

Procedure. Ad-lib water was available throughout the experiment in clear plastic bottles mounted to the right of the food hopper on the cage fronts. On Day 1, all food was removed from the cages. On Days $2-5$, the rats were fed $40 \mathrm{~g}$ every other day at $1500 \mathrm{~h}$. On Days 6-11, the rats were fed $35 \mathrm{~g}$ every other day at $1500 \mathrm{~h}$, and they remained on this feeding schedule throughout training and lesting.

The experiment was a $3 \times 2$ factorial, combining three different high and low deprivation level combinations ( 2 vs. 43 h, 2 vs. 26 h, and 24 vs. $43 \mathrm{~h}$ ) and two amounts of food containing the flavors (1 vs. $16 \mathrm{~g}$ of wet mash). The hours of food deprivation refer to hours after the 1500 -h feeding. Half of each group received banana paired with high deprivation and vanilla paired with low deprivation; the other half received the opposite flavor pairing. The $35-\mathrm{g}$ feeding was reduced to $34 \mathrm{~g}$ for those receiving $1 \mathrm{~g}$ of mash and to $19 \mathrm{~g}$ for those receiving $16 \mathrm{~g}$ of mash.

There were 12 days of training, followed by 4 days of test. The deprivation schedule continued during the 4 days of testing, so that one test trial was under low deprivation and one test trial was under high deprivation for each group. Each two-dish test consisted of a choice between banana- and vanilla-flavored mash. Enough mash was given so that all of it could not be consumed in the 10min test. Amount consumed was recorded by weighing the amount of mash remaining after the test. Left and right positions of flavored mash were randomized during testing. The ration was adjusted to $22 \mathrm{~g}$ every other day for all rats.

\section{Results}

All groups in Experiment 1 preferred the flavor experienced under the higher deprivation level, regardless of the particular deprivation levels or the amount of food given to deliver the flavor. Figure 1 shows the results.

An analysis of variance included deprivation levels $(43$ vs. $2 \mathrm{~h}, 26$ vs. $2 \mathrm{~h}$, or 43 vs. $24 \mathrm{~h}$ ), amount of food (1 vs. $16 \mathrm{~g}$ ), and which flavor was associated with the higher deprivation as between-subject variables, and flavor paired with high versus low deprivation and days as withinsubject variables. The dependent variable was amount consumed. Preference refers to different consumptions of the flavor paired with higher deprivation versus the flavor paired with lower deprivation. The greater preference for the flavor associated with the higher deprivation level was significant $[F(1,54)=26.43, p<.001]$. The preference was larger on the higher deprivation tests, although the difference was marginally significant $[F(1,54)=3.93, p=.052]$. The preference did not vary with any other variable $(F \mathbf{s}<1)$.

\section{Discussion}

The results of Experiment 1 demonstrate that rats prefer a flavor associated with wet mash eaten under higher deprivation to a flavor eaten with the same wet mash under lower deprivation, regardless of the amount of mash used to deliver the flavor. Thus, the reinforcing value of wet mash is increased by increasing food deprivation.

Fedorchak and Bolles (1987) showed that increasing deprivation in test enhanced consumption of a flavor paired with sucrose, but not a flavor paired with saccharin. They suggested that deprivation enhances consumption of flavors associated with calories. It is thus surprising that, in Experiment 1, increasing deprivation in test did not enhance consumption of flavors associated with wet mash. However, results were in the appropriate direction and parameters were not identical to those used by Fedorchak and Bolles (1987). In particular, Fedorchak and Bolles fed ad lib for $24 \mathrm{~h}$ prior to their lowdeprivation test. Perhaps the low deprivation must be fairly low for the value of food-related stimuli to be reduced. Our low deprivation was fairly high ( $2 \mathrm{~h}$ following $35 \mathrm{~g}$ of feeding).

We measured conditioned flavor preferences as a function of deprivation level using foods to deliver the flavors (as opposed to saccharin or sucrose solutions) in one previous experiment (Capaldi, 1990, Experiment 5). In that experiment, preference for a flavor given in $5 \mathrm{~g}$ of highor low-fat chow was greater if the chow was consumed under $16 \mathrm{~h}$ of deprivation than if it was consumed under $40 \mathrm{~h}$ of deprivation. There were many differences in procedure between that experiment and the present Experiment 1 that could be responsible for the difference in results. However, results of Experiment 1 also contrast with those obtained by Capaldi and Myers (1982) and Capaldi et al. (1983). In those studies using saccharin or sucrose solutions and procedures comparable to those of Experiment 1, rats preferred the flavor received under lower deprivation to that received under higher deprivation. This comparison suggests that sweetness may be important in determining whether or not conditioned food preferences are increased by high deprivation. There may be something aversive about sweetness under high deprivation, or something more reinforcing about sweetness under low deprivation. To evaluate the role of sweetness, in Experiment 2, we used sweet wet mash to deliver the flavors.

\section{EXPERIMENT 2}

In Experiment 2, all rats received one flavor of wet mash under high deprivation and a different flavor under low deprivation, just as in Experiment 1. The deprivation levels used were 2 and $43 \mathrm{~h}$ of food deprivation. Groups differed in the food used to deliver the flavors: $1 \mathrm{~g}$ of sweet wet mash, $16 \mathrm{~g}$ of sweet wet mash, or $16 \mathrm{~g}$ of plain wet mash. We expected that, with plain mash, 

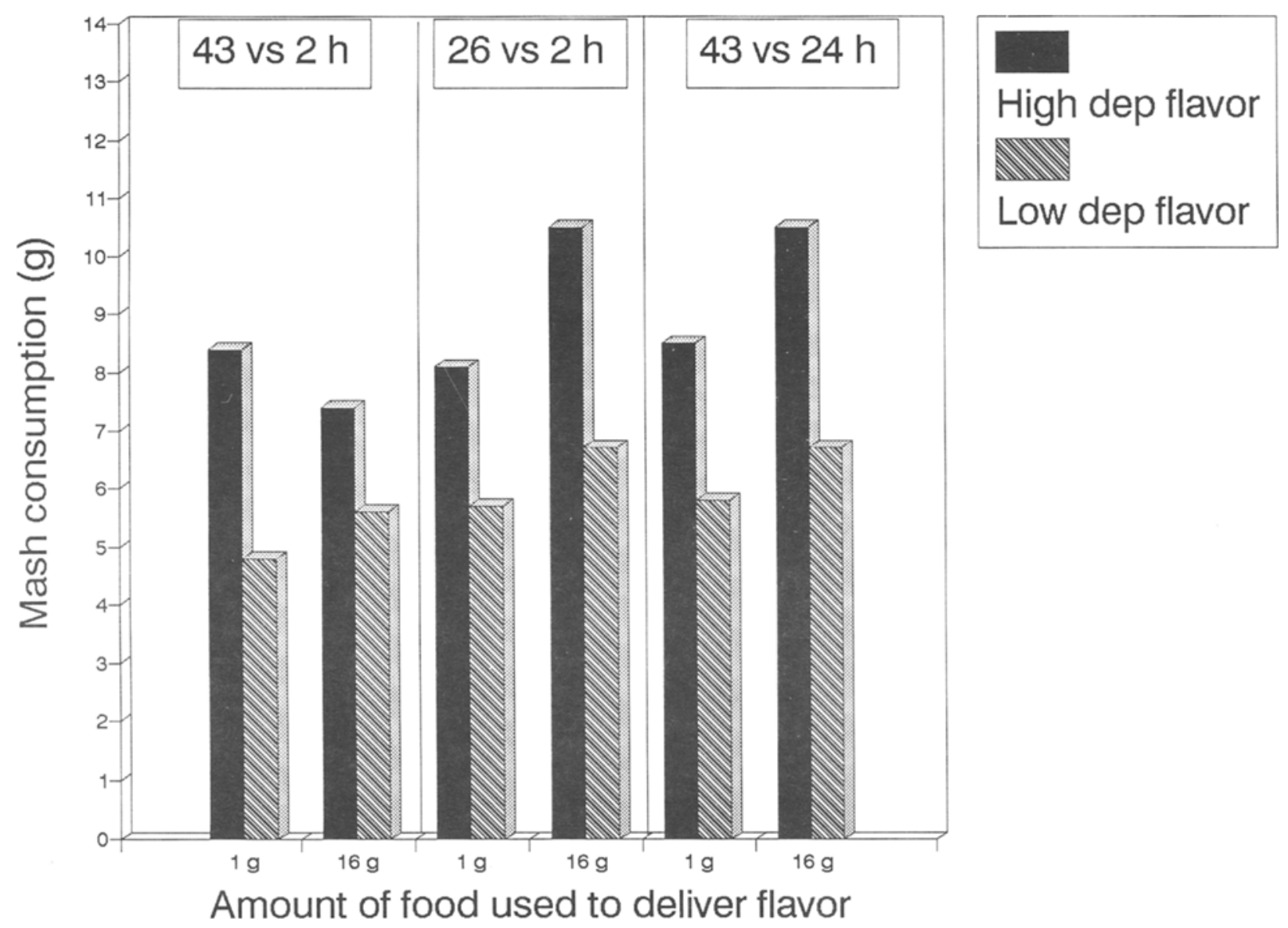

Figure 1. Mean consumption in Experiment 1 in test of the flavor of mash that had been paired with the higher and lower deprivation in training. Groups differed in the amount of food used to deliver the flavor and the hours of deprivation used as higher and lower deprivation. All mashes were unsweetened.

rats would prefer the flavor received under high deprivation to that received under low deprivation, as we found in Experiment 1. We hypothesized that sweetening the mash might eliminate or reverse this effect, if sweetness is less reinforcing under higher deprivation.

\section{Method}

Subjects. The subjects were 30 rats of the same description as those used in Experiment 1. They were 75 days old upon arrival and 78 days old at the start of the experiment.

Materials. Flavored plain mash was the same as that used in Experiment 1. Flavored saccharin mash consisted of $49.9 \%$ ground chow, $0.1 \%$ saccharin, $47 \%$ distilled water, and $3 \%$ flavoring. Flavoring consisted of $2 \%$ wintergreen oil in $100 \%$ ethanol or $2 \%$ cinnamon oil in $100 \%$ ethanol.

Procedure. The procedure was the same as that in Experiment 1, except that rats were fed $35 \mathrm{~g}$ every other day beginning on Day 2 and, in testing, groups trained with saccharin mash were tested with saccharin mash. The group trained with plain mash was tested with plain mash.

\section{Results}

Groups given $1 \mathrm{~g}$ of mash (plain or sweet) preferred the flavor experienced under higher deprivation, whereas the group given $16 \mathrm{~g}$ of sweet mash had no preference. Figure 2 shows the results. There was a highly significant group $\times$ preference interaction $[F(2,27)=8.13$, $p<.001]$. Subsequent Newman-Keuls tests showed that the preference for the flavor experienced under high deprivation was significant for each of the groups given $1 \mathrm{~g}$ of sweet or plain mash $(p<.01)$, whereas there was no preference for the group given $16 \mathrm{~g}$ of sweet mash. Group did not interact significantly with any other variable.

\section{Discussion}

The results of Experiment 2 showed that the value of a large sweet meal is not increased by increasing deprivation. The rats did consume the $16 \mathrm{~g}$ of sweet mash during training. Indeed, $16 \mathrm{~g}$ of mash is an appreciable meal, and it should be reinforcing to a food-deprived rat. The reinforcement from the amount of mash appears to be counteracted by the increased sweetness thereby encountered. That is, the large amount of sweetness in the $16 \mathrm{~g}$ of food appears to be less reinforcing with increased deprivation. It is interesting that preference was for the flavor given under high deprivation when only $1 \mathrm{~g}$ of sweet mash 


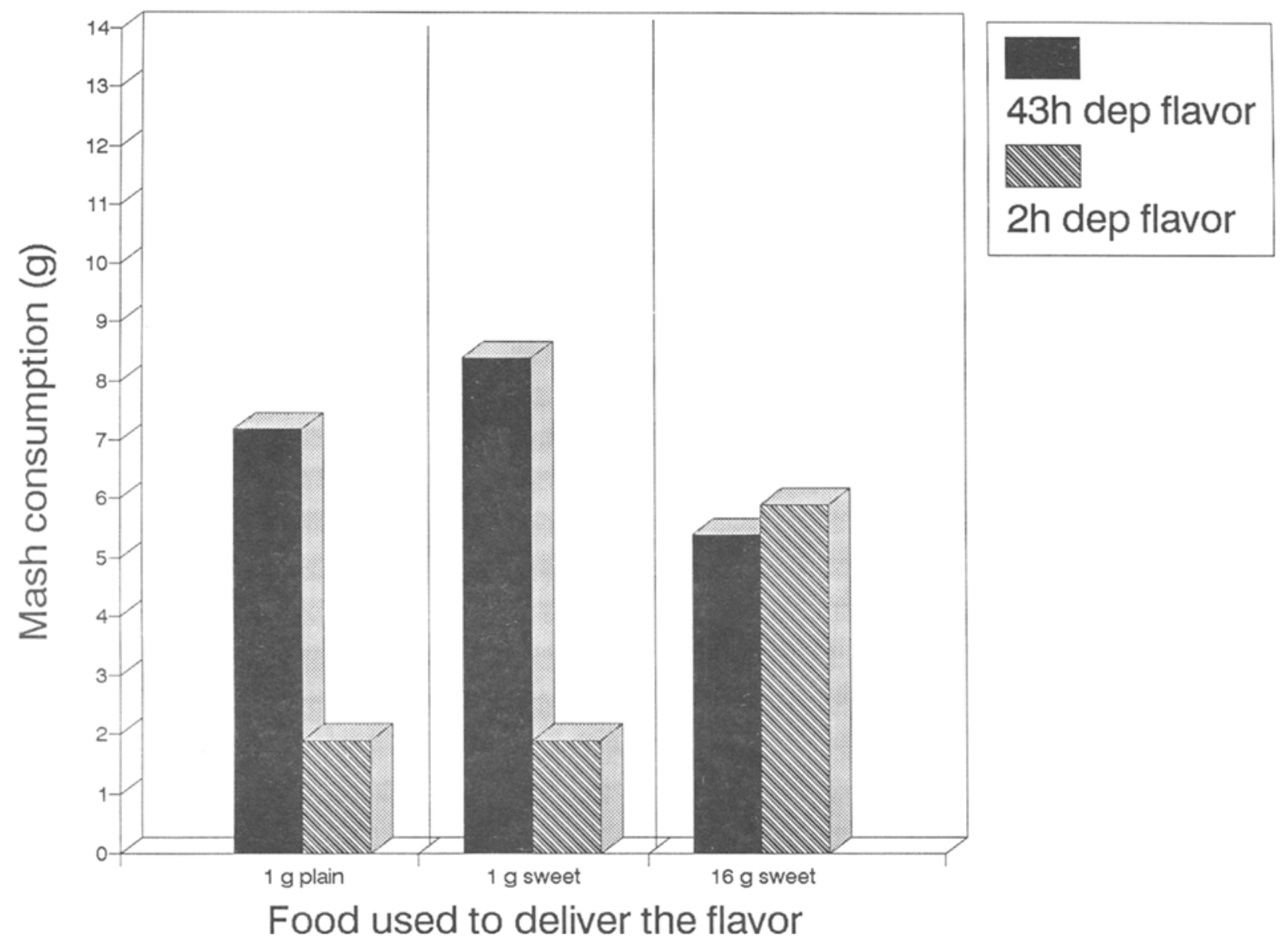

Figure 2. Mean consumption in Experiment 2 in test of the flavor of mash that had been paired with 2-or 43-h deprivation in training. In training, flavors had been delivered in 1-g plain mash, 1-g sweet mash, or 16-g sweet mash (0.1\% saccharin).

was given. Apparently, there is something aversive about large amounts of sweetness when the rat is very hungry, something that counteracts the reinforcing effect of the large meal.

\section{EXPERIMENT 3}

In Experiment 2, we used flavors in the mash (wintergreen and cinnamon) different from those used in Experiment 1 (banana and vanilla). It is conceivable that preference for the mashes as a function of deprivation could vary with the flavors associated with each deprivation. Perhaps, with banana and vanilla, there would be no preference for the high-deprivation flavor even when $16 \mathrm{~g}$ of plain mash was given. In Experiment 3, we used banana and vanilla flavors and varied the amount of plain and sweet mash used to deliver the flavors.

\section{Method}

Subjects and Procedure. The subjects were 40 naive rats of the same description as in Experiment 2 . The procedure was the same as in Experiment 2, except that four groups were run in a $2 \times 2$ factorial design including 1 versus $16 \mathrm{~g}$ of mash and plain versus sweet- ened as variables, and the flavors used were banana and vanilla. Plain mash consisted of $50 \%$ powdered chow, $47 \%$ distilled water, and $3 \%$ flavoring. Sweet mash consisted of $49.9 \%$ powdered lab chow, $0.1 \%$ saccharin, $47 \%$ distilled water, and $3 \%$ flavoring. Flavorings were the same as those used in Experiment 1.

\section{Results}

In Experiment 3, all groups showed a preference for the flavor of mash experienced under high deprivation, but the size of the preference varied with sweetness and amount of food given, such that the preference was greatest for the rats given $16 \mathrm{~g}$ of plain mash and smallest for the rats given $16 \mathrm{~g}$ of sweet mash. Figure 3 shows the results.

As can be seen in Figure 3, all groups preferred the flavor associated with higher deprivation $[F(1,30)=$ $14.29, p<.001]$. However, the size of the preference for the flavor associated with high deprivation was, in descending order, 16 plain $>1$ sweet $>1$ plain $>16$ sweet. This pattern of results produced a marginally significant preference $\times$ amount $\times$ sweetness interaction $[F(1,30)=3.95, p=.056]$. Subsequent Newman-Keuls tests showed that the preference for the high-deprivation 


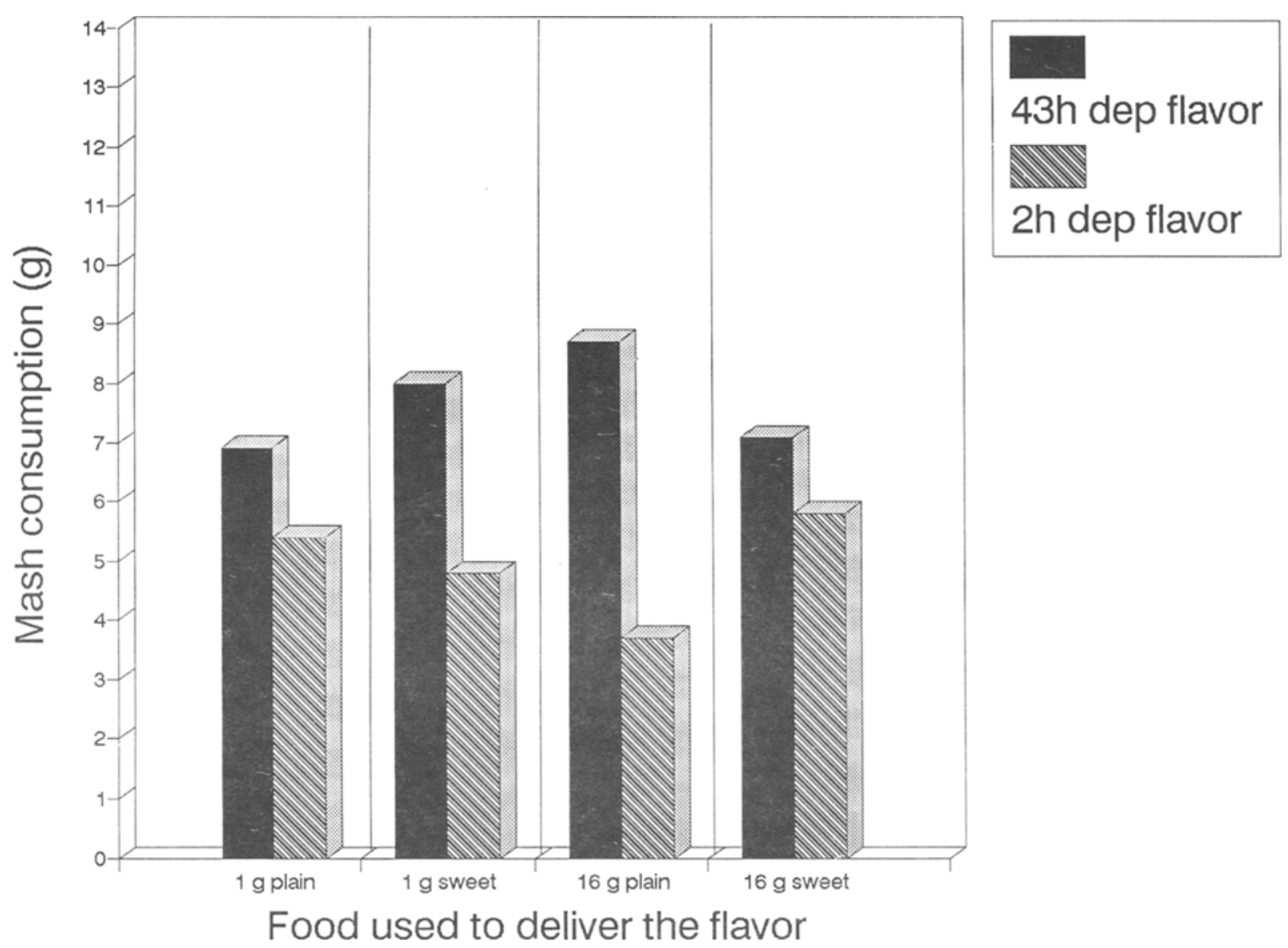

Figure 3. Mean consumption in Experiment 3 in test of the flavor of mash that had been paired with 2- or 43-h deprivation in training. In training, flavors had been delivered in 1-g plain mash, 1-g sweet mash, 16-g plain mash, or 16-g sweet mash (0.1\% saccharin).

flavor was significant for Groups 16-plain and 1-sweet, but was not significant for Groups 1-plain and 16-sweet $(p<.05)$. The pattern of data was the same on each test day, although differences were somewhat larger on the high-deprivation tests and on the second test day. On the second test day, the interaction of preference $\times$ amount $\times$ sweetness was significant $[F(1,30)=4.49, p<.05]$, using the error term from the overall analysis. Preference did not interact with test deprivation $(F<1)$ or any other variable.

\section{Discussion}

In Experiment 3, results were in the same direction as those in Experiment 2. There was a significant preference for the flavor associated with higher deprivation when a large amount of unsweetened food was used to deliver the flavors (Group 16-plain), but sweetening the food (Group 16-sweet) or reducing the amount (Group 1-plain) eliminated the preference. However, the interaction in Experiment 3 was only marginally significant. In Experiment 4 , we increased both the amount of mash given to the large-amount groups and the degree of sweetness in the sweet mash, to see if effects would be larger with a wider range of the variables.

\section{EXPERIMENT 4}

\section{Method}

Subjects and Procedure. The subjects were 40 naive rats of the same description as employed in Experiments 2 and 3. The procedure of Experiment 4 was the same as in Experiment 3, except that the saccharin concentration was increased to $0.15 \%$ and the amount of mash given to the large-amount groups was increased to $20 \mathrm{~g}$.

\section{Results}

Figure 4 shows the results. Groups given plain mash preferred the flavor of mash experienced under high deprivation, whereas groups given sweetened mash preferred the flavor experienced under low deprivation. This produced a significant preference $\times$ sweetness interaction $[F(1,30)=7.23, p<.02]$. Subsequent Newman-Keuls tests showed that the preference for the flavor associated with the higher deprivation was significant for Group 20plain, but no other group's preference was significant. Although the preference for Group 1-plain was not sig- 


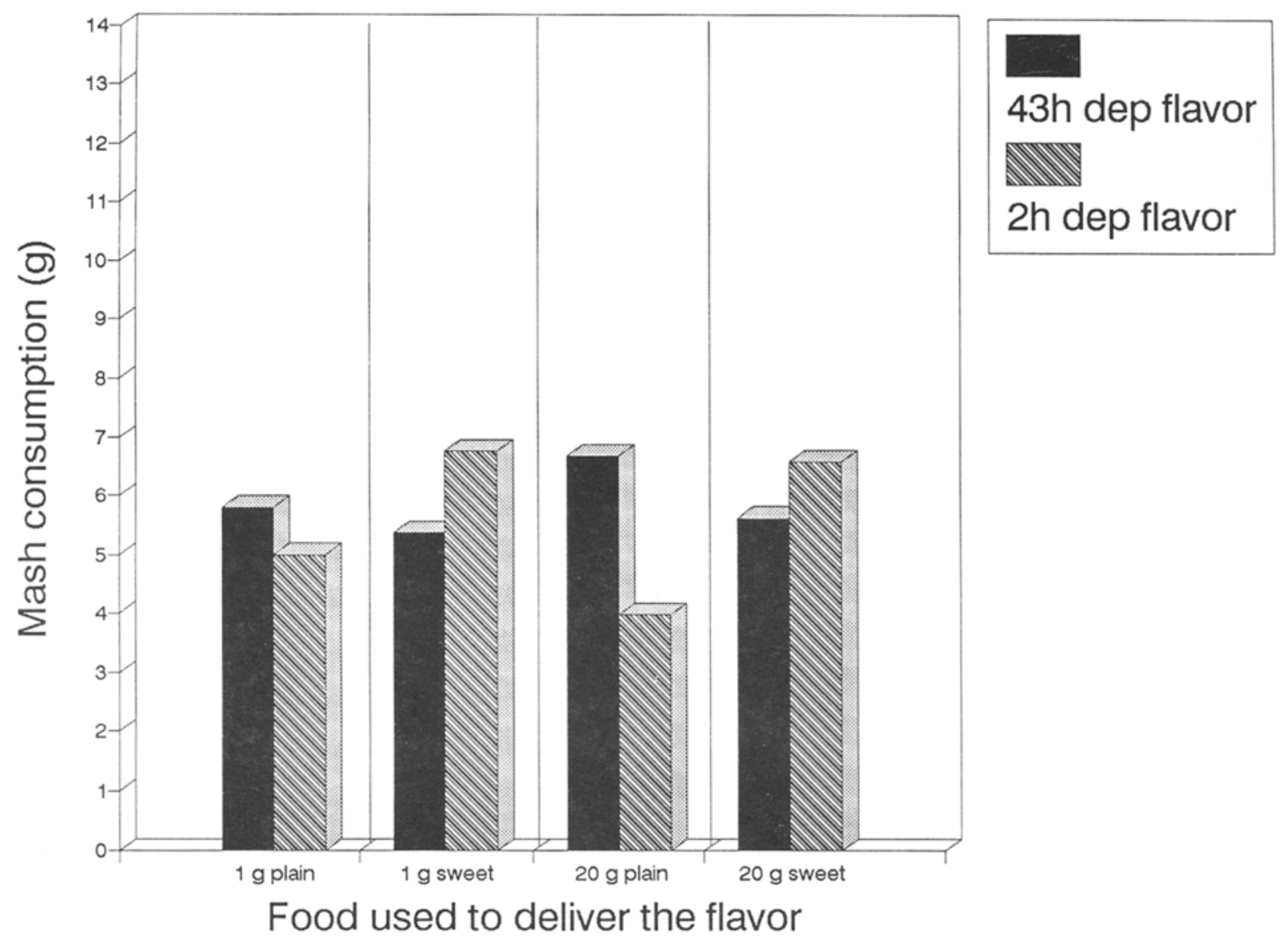

Figure 4. Mean consumption in Experiment 4 in test of the flavor of mash that had been paired with 2- or 43-h deprivation in training. In training, flavors had been delivered in 1-g plain mash, 1-g sweet mash, 20-g plain mash, or 20-g sweet mash (0.15\% saccharin).

nificant, it was also not significantly smaller than the preference shown by Group 20-plain. The preferences for the flavor associated with high deprivation for Groups 1sweet and 20-sweet were significantly smaller than the preference shown by Group 20-plain. There was no significant main effect of preference $(F<1)$, nor did preference interact significantly with any other variable, including test deprivation $(F<1)$.

\section{Discussion}

In Experiment 4 , as in the preceding experiments, the rats preferred a flavor given in plain mash under high deprivation to a flavor given in plain mash under low deprivation. Sweetening the mash eliminated this preference, whether a large or small amount of mash was given. In Experiment 4, we used a higher concentration of saccharin than we did in Experiments 2 and 3, where sweetening failed to eliminate the preference for the flavor associated with the higher deprivation in groups given $1 \mathrm{~g}$ of mash.

\section{GENERAL DISCUSSION}

The present experiments used conditioned flavor preferences to measure the reinforcing value of various eating experiences. We assumed that the higher the reinforcing value of a particular consumption experience, the greater the preference would be for a flavor associated with that experience. The results of Experiment 1 show that the reinforcing value of unsweetened food is enhanced by higher deprivation within a wide range of deprivation levels ( 2 to $43 \mathrm{~h}$ ). This enhancement of reinforcing value did not vary with amount of food ( $1 \mathrm{vs.} 16 \mathrm{~g}$ of wet mash) associated with the flavor. These results are consistent with theories of motivation that assume increasing deprivation enhances the reinforcing value of food (e.g., Bolles, 1972; Kurtz \& Jarka, 1968).

Capaldi and Myers (1982) and Capaldi et al. (1983) showed that when flavors were given in saccharin and sucrose solutions under the same conditions as in Experiment 1 , rats preferred a flavor received under low depri- 
vation to a flavor received under high deprivation. A comparison of these results with those of Experiment 1 suggested that the reinforcing value of sweetness may be reduced by higher deprivation. Consistent with this hypothesis, the results of Experiments 2, 3, and 4 show that the reinforcing value of a large sweet meal is not enhanced by higher deprivation. The results of Experiment 4 show that if enough sweetener is used, the reinforcing value of a small sweet meal is also not enhanced by higher deprivation. These data suggest that sweetness is less reinforcing under high deprivation than under low deprivation. Increasing the sweetness experienced either by giving a larger amount of sweet food or by increasing sweetness concentration eliminated the preference for the flavor experienced under higher deprivation.

The data from other studies may seem to contradict the conclusion that sweetness is less reinforcing with increased deprivation, but those studies measured effects of deprivation on performance for sweet substances, not effects of deprivation on the reinforcement produced by sweet substances. As long ago as 1944, Soulairac showed that hunger induced by insulin increased consumption of $10 \%$ solutions of maltose, sucrose, and glucose in direct proportion to their sweetness (see Soulairac, 1944). Since then, many studies have shown that hunger increases consumption of both sugar and saccharin in rats (e.g., Collier \& Bolles, 1968; Smith \& Duffy, 1957). However, these studies measured the effects of deprivation on current consumption, not the effects of deprivation on learning. Current consumption can be affected by many performance factors and is not a good measure of reinforcing effectiveness. Deprivation may enhance the current consumption of sweet substances, while not necessarily increasing the reinforcement produced by those substances.

The facilitating effects of deprivation on consumption of sweet substances may reflect an enhancement of the oral effects of sweet substances on ingestion (Davis \& Levine, 1977). Or the immediate effects of deprivation on consumption may reflect a previously learned or genetically mediated association of sweetness with calories. Booth, Lovett, and McSherry (1972) showed that the usual preference for the sweeter of two solutions can be reversed by associating the normally less preferred level of sweetness with postingestive effects of $10 \%$ glucose. Deprivation may then facilitate consumption of sweet substances because of a normal association between the sweeter substance and calories and the increased value of calories with increased deprivation (Bolles, 1983; Mook, 1974). Consistent with the latter hypothesis, Fedorchak and Bolles (1987) showed that increasing deprivation enhanced consumption of a flavor previously associated with sucrose, but not consumption of a flavor previously associated with saccharin. They suggested that deprivation only enhances consumption of flavors associated with calories. Although we did not find, in the present experiments, that deprivation enhanced consumption of a flavor associated with mash, this may be because (as we suggested above) our lower deprivation was fairly high-higher than that used by Fedorchak and Bolles (1987). Perhaps a very low deprivation is necessary before current consumption of a flavor associated with calories is inhibited.

In previous experiments measuring effects of deprivation on learning of food preferences (Capaldi, 1991), we associated one flavor with sweetened food and a second flavor with unsweetened food, both foods containing calories. In these experiments, the preference for the flavor associated with sweet food was greater the higher the deprivation in training and testing, even if the sweetened food contained fewer calories than did the unsweetened food. When one flavor is associated with sweet food and the other is not, a preexisting association between sweetness and calories (either previously learned or genetically mediated) can account for an enhancing effect of deprivation on the preference for the flavor associated with sweetness. In the present experiments, both flavors were associated with sweetness for the rats given sweet foods. Under these conditions, a differential association of sweetness with calories cannot play a role, and, when this was the case, the reinforcing effect of sweetness was not increased by deprivation. Indeed, sweetening the food eliminated the preference for flavors consumed under higher deprivation, suggesting that the reinforcing effect of sweetness is decreased by higher deprivation.

The present results suggest that the reinforcing value of sweetness does not increase with increasing deprivation. Thus, the reinforcing effects of all foods and foodrelated stimuli do not increase with increasing deprivation. The appropriate question for further research is to ask how the reinforcing effects of various foods and food elements change as a function of deprivation level, including a wide range of deprivation levels.

\section{REFERENCES}

Bolles, R. C. (1972). Reinforcement, expectancy, and learning. Psychological Review, 79, 394-409.

Bolles, R. C. (1983). A "mixed" model of taste preference. In R. L. Mellgren (Ed.), Animal cognition and behavior (pp. 65-83). Amsterdam: North-Holland.

Booth, D. A., LOVetT, D., \& McSherry, G. M. (1972). Postingestive modulation of the sweetness preference gradient in the rat. Journal of Comparative \& Physiological Psychology, 78, 485-512.

CAPAlDI, E. D. (1990). Hunger and conditioned flavor preferences. In E. D. Capaldi \& T. L. Powley (Eds.), Taste, experience, and feeding (pp. 157-169). Washington, DC: American Psychological Association.

CAPALDI, E. D. (1991) Hunger and the learning of flavor preferences. In R. C. Bolles (Ed.), The hedonics of raste (pp. 127-142). Hillsdale, NJ: Erlbaum

CaPaldi, E. D., \& MYers, D. E. (1982). Taste preferences as a function of food deprivation during original taste exposure. Animal Leaming \& Behavior, 10, 211-219.

Capaldi, E. D., Myers, D. E., Campeell, D. H., Sheffer, J. D. (1983). Conditioned flavor preferences based on hunger level during original flavor exposure. Animal Learning \& Behavior, 11, 107-115. Coluer, G., Bolles, R. C. (1968). Hunger, thirst, and their inter- 
action as determinants of sucrose consumption. Joumal of Comparative \& Physiological Psychology, 66, 633-641.

Davis, J. D., Levine, M. W. (1977). A model for the control of ingestion. Psychological Review, 84, 379-412.

Fedorchax, P. M., Bolles, R. C. (1987). Hunger enhances the expression of calorie- but not taste-mediated conditioned flavor preferences. Joumal of Experimental Psychology: Animal Behavior Processes, 13, 73-79.

Kurtz, K. H., Jarka, R. G. (1968). Position preference based on differential food deprivation. Joumal of Comparative \& Physiological Psychology, 66, 518-521.

Mook, D. G. (1974). Saccharin preference in the rat: Some unpalatable findings. Psychological Review, 81, 475-490.
Revusky, S. H. (1967). Hunger level during food consumption: Effects on subsequent preference. Psychonomic Science, 7, 109-110. Smith, M., \& DUFFY, M. (1957). Consumption of sucrose and saccharin by hungry and satiated rats. Journal of Comparative \& Physiological Psychology, 50, 65-69.

Soulairac, A. (1944). Action de L'insuline dur la consommation de différents glucides chez la souris. Comptes Rendus de la Société de Biologie, 138, 119-120.

(Manuscript received November 6, 1990; revision accepted for publication June 10, 1991.) 